\title{
Qualidade química de frutos do maracujazeiro-amarelo em solo com biofertilizante irrigado com águas salinas
}

\author{
Thiago J. Dias ${ }^{1}$, Lourival F. Cavalcante ${ }^{2}$, José L. de 0 . Freire ${ }^{3}$, José A. M. do Nascimento ${ }^{2}$, \\ Márkilla Z. Beckmann-Cavalcante $\&$ G audêncio P. dos Santos ${ }^{2}$
}

\begin{abstract}
RESU MO
U m experimento foi desenvolvido para avaliar os efeitos da salinidade da água de irrigação e frequên cias de aplicação de biofertilizante bovino no solo sobre as qualidades químicas de frutos de maracujazeiroamarelo. Os tratamentos foram distribuídos em arranjo fatorial $5 \times 4$, correspondendo aos valores de condutividade elétrica da água de irrigação: 0,$5 ; 1,5 ; 2,5 ; 3,5$ e 4,5 dS $\mathrm{m}^{-1}$ e a quatro frequências de aplicação do biofertilizante: sem a aplicacão do biofertilizante (SB); aplicação realizada uma semana antes do transplantio (1 SAT); a cada 90 dias a partir do transplantio (90 DAT); uma semana antes do transplantio e a cada 90 dias após o transplantio (1 SAT + 90 DAT). Pelos resultados se certifica de que o aumento da salinidade da água inibiu o rendimento em polpa, os teores de sólidos solúveis (SS), o pH, a razão sólidos solúveis/acidez titulável (SS/AT) e os teores de vitamina "C" no suco, proporcionando maior acidez e elevação da condutividade elétrica do suco. 0 aumento da frequência de aplicação do biofertilizante, apesar de aumentar a condutividade elétrica do suco atenuou os efeitos degenerativos dos sais da água de irrigação às plantas, resultando em incremento no rendimento em polpa, teores de vitamina " $\mathrm{C}$ " e ainda reduziu a razão SS/AT e o pH da polpa.
\end{abstract}

Palavras-chave: Passiflora edulis L., caracterização, salinidade, efluente orgânico

\section{Chemical quality of yellow passion fruit in soil with biofertilizer and irrigated with saline water}

\section{ABSTRACT}

This work had the objective to evaluate the effects of irrigation water salinity (EC) associated to application frequencies of bovine biofertilizer on chemical qualities of yellow passion fruits. The treatments were distributed using $5 \times 4$ factorial design corresponding the five EC of irrigation plant water of $0.5,1.5,2.5$, 3.5 and $4.5 \mathrm{dS} \mathrm{m}^{-1}$, in four frequencies of application of the biofertilizer: without bovine biofertilizer (SB); with application one week before transplanting (1 SAT); application with intervals of 90 days after transplanting (90 DAT); and, with application one week before transplanting and at intervals of 90 days (1 SAT + 90 DAT). From the results it is verified that the increased salinity of water inhibited the pulp yield, the total soluble solids (TSS), $\mathrm{pH}$, the ratio of total soluble solids and titratable acidity (TSS/AT) and vitamin " $C$ "in juice, providing increased acidity and electrical conductivity of the juice. The increased frequency of application of the biofertilizer, despite increasing the electrical conductivity of the juice diminished the degenerative effects of salts of irrigation water to plants, resulting in an increase in pulp yield, vitamin " $\mathrm{C}$ " and also reduced the ratio TSS/AT and the $\mathrm{pH}$ of the pulp of yellow passion fruit.

Key words: Passiflora edulis, characterization, salinity, biofertilizer 


\section{INTRODUÇÃO}

O Brasil é o maior produtor e consumidor mundial do maracujazeiro-amarelo (Passiflora edulis f. flavicarpa Deg), com produção de 614 mil toneladas em uma área de 45.300 ha, destacando-se no agronegócio da produção de frutas e contribuindo para o desenvolvimento do setor agrícola (Sampaio et al., 2008, AGRIANUAL, 2009). Nos últimos anos, embora a expansão da área cultivada com maracujazeiro tenha sido motivada, entre outros fatores, pelo aumento do consumo interno da fruta in natura e pelo suco processado, a produção nacional não supriu a demanda do mercado agroindustrial (Pimentel et al., 2009).

Para obtenção de frutos de qualidade química que satisfaçam as exigências de consumidores e da indústria de processamento de polpa, os produtores de maracujá-amarelo, principalmente das regiões Norte e Nordeste devem utilizar tecnologias apropriadas que possibilitem suprir suas limitações hidroclimáticas e ambientais com a adoção do manejo adequado da irrigação (Soares et al., 2008; Porto Filho et al., 2009). Essas regiões são caracterizadas por condições de elevada demanda evapotranspirativa, reduzido índice pluviométrico, uso inadequado da drenagem e utilização de água e do solo com teores elevados de sais (Silva et al., 2009) que, muitas vezes, provocam modificações morfológicas, estruturais e metabólicas das culturas, afetando os processos germinativos, provocando heterogeneidade das mudas e desuniformidade no crescimento das plantas (Gurgel et al., 2003; 2010), com reflexos negativos na capacidade produtiva e qualidade dos frutos.

Em geral, as perdas no rendimento e na qualidade da produção das plantas variam entre as espécies e cultivares, que apresentam comportamento fisiológico diferenciado quanto aos efeitos da salinidade no solo e na água. Esta influência é dependente do estádio fenológico da cultura, duração da exposição ao estresse salino, dos sais presentes no meio, condições ambientais, propriedades do solo, tipo e intensidade do manejo do solo e da cultura (Maas, 1990; Cavalcante et al., 2005).

O maracujazeiro-amarelo, conforme Maas (1990) e Ayers \& Westcot (1999) apresenta elevada sensibilidade à ação dos sais. Entretanto, algumas pesquisas têm demonstrado que, apesar da salinidade provocar reflexos negativos no crescimento, na capacidade produtiva da cultura e na qualidade dos frutos (Soares et al., 2008; Cavalcante et al., 2009), a utilização de fertilizantes orgânicos, como o biofertilizante bovino, pode amenizar os efeitos da salinidade da água de irrigação, resultando em maior desenvolvimento das mudas e produção das plantas (Souza et al., 2008; Cavalcante et al., 2010).

Apesar dos resultados promissores quanto à utilização do biofertilizante na agricultura, ainda são escassos, na literatura, artigos relacionados à qualidade química dos frutos de maracujazeiro-amarelo, produzidos em condições de salinidade e biofertilizante (Cavalcante et al., 2003; 2006; Rodolfo Júnior et al., 2008).

Pelo exposto, a realização de pesquisas que possam reduzir as limitações de produção, como a adoção de tecnologias para o manejo irrigado com águas salinas, pode proporcionar a produção de frutos de qualidade (Costa et al., 2001; Cavalcante et al., 2003). Esta alternativa pode favorecer a consolidação da atual posição do Brasil como o maior produtor da fruta de maracujazeiro-amarelo (Silva et al., 2008) e maior exportador de suco concentrado e polpa de maracujazeiro que, juntamente o com a Colômbia, Equador e Peru, responde por $90 \%$ do mercado mundial (AGRIANUAL, 2009).

O objetivo do trabalho foi avaliar os atributos químicos de frutos do maracujazeiro-amarelo (Passiflora edulis $\mathrm{f}$. flavicarpa Deg) sob irrigação com águas salinas e frequências de aplicação de biofertilizante bovino fornecido ao solo, na forma líquida.

\section{Material E MÉTODOS}

O experimento foi conduzido em pomar de campo aberto instalado em setembro de 2008, no município de Remígio, PB, na propriedade Macaquinhos, georreferenciado pelas coordenadas $6^{\circ} 53^{\prime} 00^{\prime \prime}$ de latitude Sul, $36^{\circ} 02^{\prime} 00^{\prime \prime}$ de longitude Oeste e altitude de $470 \mathrm{~m}$. Segundo Köppen, adaptado ao Brasil (Coelho \& Soncin, 1982), o clima do município é do tipo As', quente e úmido. No período experimental foram registradas médias de temperatura do ar de $25^{\circ} \mathrm{C}$, umidade relativa de $80 \%$ e precipitação de $205 \mathrm{~mm}$.

Os tratamentos foram distribuídos em blocos casualizados, com três repetições, adotando-se o arranjo fatorial 5 x 4, referente aos valores de salinidade da água de irrigação de 0,5 ; 1,$5 ; 2,5 ; 3,5$ e 4,5 dS m${ }^{-1}$, em quatro frequências de aplicação de biofertilizante bovino: sem a aplicação do biofertilizante (SB); aplicação uma semana antes do transplantio (1 SAT); aplicação a cada 90 dias após o transplantio (90 DAT) e aplicação uma semana antes e a cada 90 dias após o transplantio (1 SAT +90 DAT). As parcelas foram representadas pelo valor da condutividade elétrica (salinidade da água de irrigação) e as subparcelas, constituídas por três plantas, referentes às frequências de aplicação do biofertilizante.

As mudas foram transplantadas quando atingiram $25-35 \mathrm{~cm}$ de altura, cinco a seis pares de folhas e na ocasião da emissão das primeiras gavinhas. A sustentação das plantas foi por espaldeira a $2,2 \mathrm{~m}$ de altura do solo e o plantio foi realizado no espaçamento $3 \times 3 \mathrm{~m}$, em recipientes de polietileno utilizados como lisímetros, com 60 e $50 \mathrm{~cm}$ de altura e diâmetro, respectivamente, e capacidade para $158 \mathrm{dm}^{3}$ de substrato. $\mathrm{O}$ substrato foi preparado a partir da mistura de um solo de textura arenosa ( $85 \%$ areia, $9,5 \%$ silte e $9,5 \%$ argila) e esterco bovino curtido, nas proporções de 9:1. As características químicas e a caracterização do substrato quanto à salinidade, são apresentadas, respectivamente, nas Tabelas 1 e 2 .

As plantas foram irrigadas diariamente, às 7 horas da manhã, com cada tipo de água, através do sistema de irrigação localizado por gotejamento. Em cada planta cova foram instalados, no sentido Leste - Oeste, dois gotejadores tipo Catife, com vazão de $3,75 \mathrm{~L} \mathrm{~h}^{-1}$, cada um a $20 \mathrm{~cm}$ do caule, com fornecimento de lâmina estimado a partir da evaporação medida em tanque classe "A" e o estádio de desenvolvimento da cultura. Objetivando promover a saturação homogênea dos solos nos lisímetros, adicionaram-se $20 \%$ do valor da lâmina 
Tabela 1. Características químicas do substrato quanto à fertilidade

\begin{tabular}{cccccccccccccc}
\hline $\mathbf{p H}$ & $\mathbf{P}$ & $\mathbf{K}^{+}$ & & $\mathbf{C a}^{2+}$ & $\mathbf{M g}^{2+}$ & $\mathbf{N a}^{+}$ & $\mathbf{H}^{+}+\mathbf{A l}^{3+}$ & $\mathbf{A l}^{3+}$ & $\mathbf{S B}$ & $\mathbf{C T C}$ & $\mathbf{M 0}$ \\
$\mathbf{1 , 0 : 2 , 5}$ & \multicolumn{2}{c}{$\mathbf{m g ~ d m}^{-3}$} & & & & $\mathbf{c m o l}_{\mathbf{c}} \mathbf{d m}^{-3}$ & & & & \\
7,36 & 216 & 666 & 3,37 & 0,90 & 2,02 & 2,25 & 0,00 & 7,99 & 10,24 & 14,84 \\
\hline
\end{tabular}

SB - soma de bases; CTC - capacidade de troca catiônica; MO - matéria orgânica

Tabela 2. Análise do substrato quanto a salinidade

\begin{tabular}{|c|c|c|c|c|c|c|c|c|c|c|c|}
\hline \multirow{2}{*}{$\mathrm{pH}$} & CE & RAS & PST & $\mathrm{Ca}^{2+}$ & $\mathrm{Mg}^{2+}$ & $\overline{\mathbf{K}^{+}}$ & $\mathrm{Na}^{+}$ & $\mathrm{SO}_{4}{ }^{2-}$ & $\mathrm{CO}_{3}{ }^{2-}$ & $\mathrm{HCO}_{3}{ }^{-}$ & $\mathrm{Cl}^{-}$ \\
\hline & $\mathrm{dS} \mathrm{m}^{-1}$ & $\mathrm{mmol} \mathrm{L}^{-1}$ & \multicolumn{9}{|c|}{$\mathrm{mmol}_{\mathrm{c}} \mathrm{L}^{-1}$} \\
\hline 7,72 & 7,84 & 6,94 & 10,21 & 10,25 & 11,63 & 14,79 & 40,04 & 7,41 & 1,82 & 14,52 & 53,67 \\
\hline
\end{tabular}

CE - Condutividade elétrica a $25^{\circ} \mathrm{C}$; RAS - Razão de adsorção de sódio $\left[\mathrm{Na}^{+} /\left(\mathrm{Ca}^{2+}+\mathrm{Mg}^{2+} / 2\right)^{1 / 2}\right] ;$ PST - $\left[\mathrm{Na}^{+} / \mathrm{Capacidade}\right.$ de troca catiônica (CTC)].100; e, ADL - Aquém do limite de detecção

estimada pela evapotranspiração de referência (Gondim et al., 2009).

O biofertilizante bovino foi preparado via fermentação anaeróbica, em recipiente hermeticamente fechado durante 30 dias (Santos \& Akiba, 1996), utilizando-se partes iguais de esterco fresco de bovino e água não salina $\left(\mathrm{CE}_{\mathrm{a}} \leq 0,5 \mathrm{dS} \mathrm{m}^{-1}\right)$.

Antes de cada aplicação o biofertilizante foi diluído em água não salina $\left(\mathrm{CE}_{\mathrm{a}} \leq 0,5 \mathrm{dS} \mathrm{m}^{-1}\right)$ na proporção de $1: 1$, procedendo após diluição, avaliação do biofertilizante como água para irrigação (Tabela 3) e aplicado via solo, a nível de $10 \%$ do volume do lisímetro.

A adubação de fundação foi realizada durante o acondicionamento do substrato nas covas, com o objetivo de elevar os teores de $\mathrm{P}_{2} \mathrm{O}_{5}$ para valores altos, conforme a textura do solo (Ribeiro et al., 1999), e médios os níveis de potássio relativos à presença do íon cloreto na água de irrigação (Cavalcante et al., 2006). Com base nas análises químicas (Tabela 1) e físicas do solo, aplicou-se 60 e $30 \mathrm{~g} \mathrm{cova}^{-1} \mathrm{de}_{2} \mathrm{O}_{5}$ e $\mathrm{K}_{2} \mathrm{O}$, respectivamente utilizando-se como fonte, superfosfato triplo $\left(40 \% \mathrm{P}_{2} \mathrm{O}_{5}\right)$ e cloreto de potássio $\left(58 \% \mathrm{~K}_{2} \mathrm{O}\right)$.

$\mathrm{O}$ manejo fitossanitário e o combate às plantas invasoras foram realizados através de monitoramento visual aplicandose, quando necessário, agente químico de controle, visando reduzir a incidência dos agentes agressores. Os tratos culturais necessários, como manejo de podas de condução e de limpeza da cultura foram, realizados de acordo com o crescimento e a necessidade estabelecida pela cultura.

Os frutos foram colhidos em março de 2009, quando apresentavam completo estado de maturação; em seguida, foram obtidos o rendimento em polpa, pela relação entre a massa da polpa e a massa do fruto, o pH do suco, determinado em pHmetro de mesa GLP - Iones Seletivos - Modelo HI 253, Hanna Instruments, cujo princípio foi a determinação da concentração hidrogeniônica $(\mathrm{pH})$, e os teores de sólidos solúveis (SS - ${ }^{\circ}$ Brix), utilizando-se o refratômetro digital portátil e bancada RTDS-28, Instrutherm Brasil. A acidez titulável (AT) foi determinada em $10 \mathrm{~mL}$ do suco, $1 \mathrm{~mL}$ de fenolftaleína e titulação com NaOH a 0,1 N (Instituto Adolfo Lutz, 1985). Obtevese a razão SS/AT pela relação direta dos teores de sólidos solúveis e acidez titulável. A vitamina "C" foi quantificada por titulometria, através de solução de DFI (2,6 diclo-fenolindofenol), utilizando-se $1 \mathrm{~mL}$ de suco diluído em $50 \mathrm{~mL}$ de ácido oxálico a 0,5\%, de acordo com Freitas et al. (2006). Avaliou-

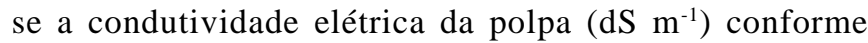
procedimentos metodológicos de Silva et al. (2009).

Os dados foram submetidos à análise de variância pelo teste $\mathrm{F}_{0,05^{*}}$, e a comparação de médias, quando significativas, foi analisada por regressão polinomial, utilizando-se o programa SAS versão 8.0 (SAS, 2000).

\section{RESULTADOS E DisCUSSÃO}

O aumento da condutividade elétrica da água de irrigação $\left(\mathrm{CE}_{\mathrm{a}}\right)$ proporcionou, estatisticamente, decréscimo no rendimento de polpa dos frutos de 47,04 para $44,87 \%$, entre as águas de 0,5 e $4,5 \mathrm{dS} \mathrm{m}^{-1}$ (Figura 1A). Da referida figura se constata comportamento inverso do biofertilizante em relação aos efeitos das águas salinas, em que o aumento da frequência de aplicação do insumo orgânico estimulou o aumento do rendimento em polpa dos frutos.

Comparativamente e apesar de evidenciada tendência de incremento dos valores de rendimento em polpa dos frutos colhidos (Figura 1A), registrou-se diferença estatística apenas nas plantas com as aplicações realizadas uma semana antes e a cada 90 dias após o transplantio (1 SAT + 90 DAT), que foi $3,5 \%$ superior a média dos tratamentos sem o insumo, com a aplicação do biofertilizante bovino, apenas uma semana antes do transplantio (1 SAT) e com as aplicações a cada 90 dias após o transplantio (90DAT). Esses resultados expressam que o biofertilizante não evita, mas atenua a ação deletérica da salinidade da água ao maracujazeiro-amarelo durante o período da formação e crescimento dos frutos (Cavalcante et al., 2009; Silva et al., 2009).

Os valores do rendimento em polpa dos frutos variam de 47,2 a 44,8\% com o aumento da salinidade da água e se situam na faixa média de 46,49\% apresentada por Fischer et al. (2007) em cultivo tradicional da cultura mas inferiores aos $49,72 \%$

Tabela 3. Análise química do biofertilizante bovino líquido para irrigação

\begin{tabular}{|c|c|c|c|c|c|c|c|c|c|c|c|c|}
\hline \multirow{2}{*}{$\mathrm{pH}$} & $\mathrm{CE}$ & RAS & $\mathrm{Ca}^{2+}$ & $\mathrm{Mg}^{2+}$ & $\mathrm{K}^{+}$ & $\mathrm{Na}^{+}$ & SC & $\mathrm{SO}_{4}{ }^{2-}$ & $\mathrm{CO}_{3}{ }^{2-}$ & $\mathrm{HCO}_{3}{ }^{-}$ & $\mathrm{Cl}^{-}$ & SA \\
\hline & $\mathrm{dS} \mathrm{m}^{-1}$ & $\mathrm{mmol} \mathrm{L}^{-1}$ & \multicolumn{10}{|c|}{$\mathrm{mmol}_{\mathrm{c}} \mathrm{L}^{-1}$} \\
\hline 6,55 & 2,76 & 3,41 & 4,13 & 7,02 & 7,98 & 8,03 & 27,16 & 5,08 & ALD & 1,12 & 1,81 & 28,01 \\
\hline
\end{tabular}

CE - Condutividade elétrica a $25^{\circ} \mathrm{C}$; RAS - Razão de adsorção de sódio $\left[\mathrm{Na}^{+} /\left(\mathrm{Ca}^{2+}+\mathrm{Mg}^{2+} / 2\right)^{1 / 2}\right]$; SC - soma de cátions; SA - soma de ânions; ALD - Aquém do limite de detecção 
A.

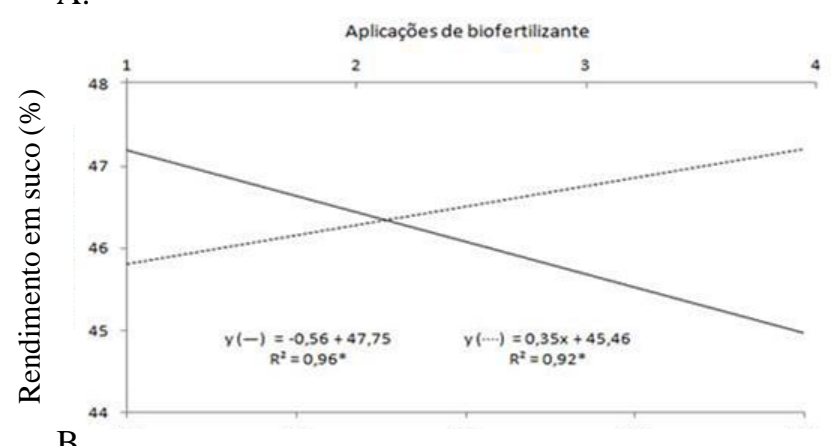

B.

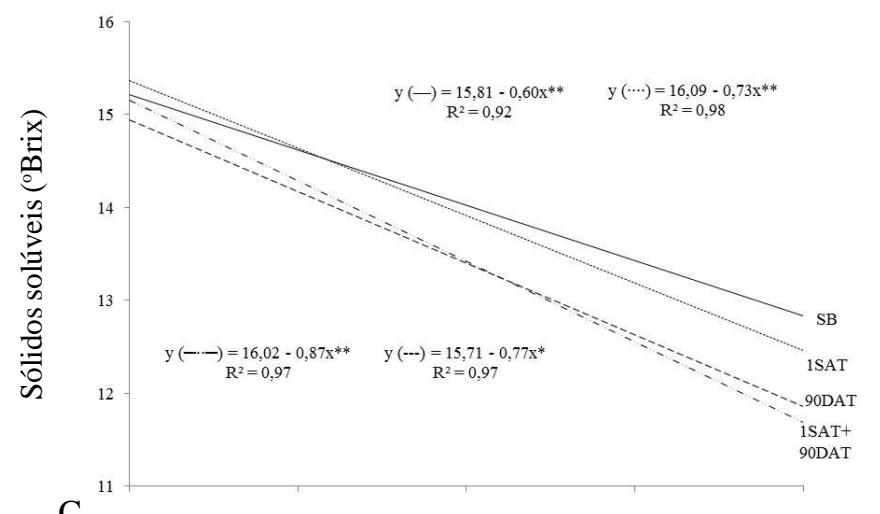

C.

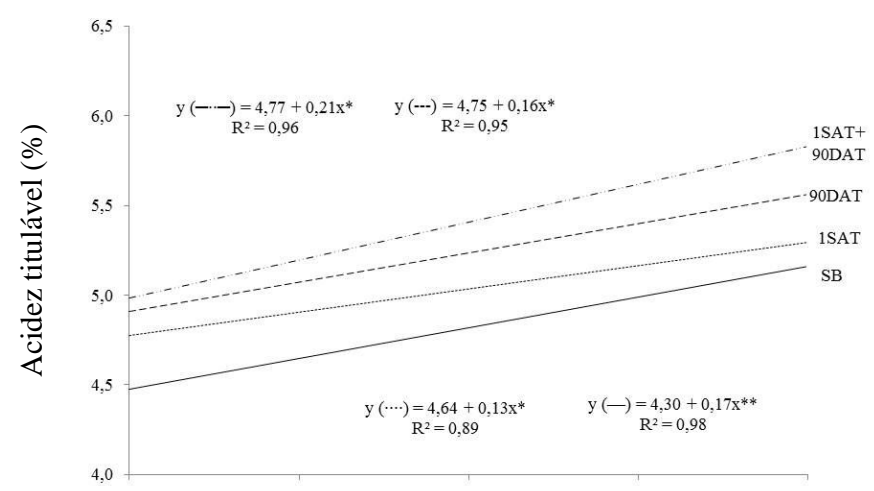

D.

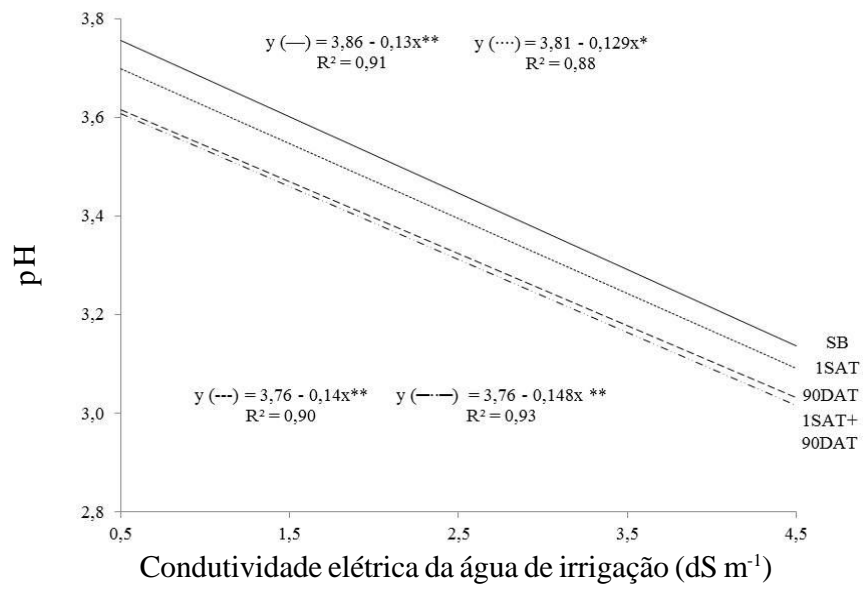

Figura 1. Valores do rendimento em polpa (A) de frutos de maracujazeiro amarelo irrigado com águas sal inas (----) em diferentes frequências de aplicação de biofertilizante (....) e teores de sólidos solúveis (B), acidez titulável (C) e pH em polpa (D) de frutos de maracujazeiro-amarelo irrigado com águas salinas em diferentes frequências de aplicação de biofertilizante obtidos por Costa et al. (2001) sob irrigação com água salina com $\mathrm{Ce}_{\mathrm{a}}$ de 3,2 $\mathrm{dS} \mathrm{m}^{-1}$. Os resultados, apesar de inferiores a $50 \%$, que deve ser o valor mínimo do rendimento em polpa de frutos de maracujá-amarelo (Meletti et al., 2002), indicam que os frutos estão próximo de atingirem as exigências do mercado consumidor, nessa variável.

O teor de sólidos solúveis foi reduzido com o aumento da condutividade elétrica da água de irrigação e com a frequência de biofertilizante ao solo (Figura 1B). A adição de sais à água de irrigação provocou redução média de $0,74^{\circ}$ Brix por aumento unitário da $\mathrm{Ce}_{\mathrm{a}}$, havendo diferença estatística entre as condutividades, superior a $1,5 \mathrm{dS} \mathrm{m}^{-1}$. Os valores variaram de 14,02 ${ }^{\circ}$ Brix nos tratamentos sem o insumo orgânico e com aplicação uma semana antes do transplantio, para $13,41^{\circ}$ Brix nos tratamentos com o biofertilizante bovino aplicado a cada 90 dias (90 DAT) e uma semana antes e a cada 90 dias após o transplantio (1 SAT + $90 \mathrm{DAT})$. O comportamento dos dados é discordante dos obtidos por Costa et al. (2001), ao afirmarem que a irrigação com água de salinidade superior a $3 \mathrm{dS} \mathrm{m}^{-1}$ não influenciou no teor de ${ }^{\circ}$ Brix da polpa de frutos de maracujazeiroamarelo em covas abertas, sem impedimento de percolação e fluxo lateral.

Comparativamente com os sólidos solúveis obtidos de frutos de maracujá-amarelo irrigados com água de condutividade elétrica de $0,5 \mathrm{dS} \mathrm{m}^{-1}$, os teores de Brix são semelhantes aos 14,5 e $13,29^{\circ}$ Brix obtidos por Cavalcante et al. (2005) utilizando irrigação com águas de conteúdos crescentes de sais sob diferentes formas de cultivo, e por Rodrigues et al. (2008), em maracujazeiro-amarelo tratado com diferentes doses de aplicação de biofertilizante bovino, na ausência e presença de potássio.

Apesar da preferência por valores acima de $15{ }^{\circ}$ Brix, conforme preconizam Meletti et al. (2002), a grande maioria dos frutos de maracujazeiro-amarelo produzidos no Brasil, apresenta teor de sólidos solúveis na polpa, abaixo deste valor. Em relação ao cultivo convencional, Tocchini et al. (1994), Silva et al. (2002), Pinheiro et al. (2006) e Medeiros et al. (2009) obtiveram, respectivamente, os valores de 12,7, 12, 12,2 e 14,5 ${ }^{\circ}$ Brix, em frutos de plantas irrigadas com águas salinas os teores não sofrem grandes variabilidades, como indicam os $14,69^{\circ} \mathrm{Brix}$ de Costa et al. (2001), 14,32 ${ }^{\circ}$ Brix de Cavalcante et al. (2005) e em solo com biofertilizante irrigado com água salina os 13,98 ${ }^{\circ}$ Brix apresentados por Cavalcante et al. (2003).

A acidez titulável da polpa dos frutos aumentou com o teor salino das águas de irrigação e com a frequência de aplicação do biofertilizante (Figura 1C).

O aumento da condutividade elétrica da água de irrigação associada às maiores frequências de aplicação do biofertilizante, deve ter elevado os teores de $\mathrm{Na}^{+} \mathrm{e} \mathrm{Cl}^{-}$nos tecidos foliares que, provavelmente, inibindo a atividade dos compostos orgânicos nas plantas do maracujazeiro-amarelo e modificando os processos bioquímicos e a fisiologia das plantas em consequência do estresse salino da água resultou em alterações das atividades fotossintéticas e na taxa de translocação de assimilados, que podem ter influenciado nos atributos qualitativos dos frutos, como os teores de sólidos solúveis e a acidez titulável (Tester \& Davenport, 2003; Marinho et al., 2005; Taiz \& Zeiger, 2006). 
Os valores da acidez titulável superaram os 3,7 e 4,6\% obtidos de frutos de plantas irrigadas com águas salinas, por Costa et al. (2001) e Cavalcante et al. (2005). Quanto aos efeitos do biofertilizante, os valores estão compatíveis com os 4,5\% apresentados por Araújo et al. (2008) e os 4,1\% por Rodrigues et al. (2008), em maracujazeiro-amarelo tratado sob diferentes dosagens de biofertilizante bovino e supermagro, respectivamente. Esta situação parece coerente com a apresentada por Fischer et al. (2007) ao afirmarem que os insumos orgânicos proporcionaram aumento de 5,15\% na acidez titulável do suco de maracujá-amarelo, em relação ao manejo convencional do solo. Teores elevados de ácido na composição dos frutos revelam tratar-se de uma característica desejável ao processamento industrial, visto que diminuem a adição de acidificantes artificiais e, consequentemente, reduzem os custos para o processamento e aumentam a vida útil do suco (Andrade \& Andrade, 2004).

$\mathrm{O}$ aumento da salinidade das águas de irrigação e da frequência de aplicação do biofertilizante reduziu o $\mathrm{pH}$ da polpa dos frutos (Figura 1D). Quanto aos efeitos do biofertilizante, os valores do $\mathrm{pH}$ em polpa decresceram de 3,$88 ; 3,83 ; 3,71$ e 3,69 para 3,$19 ; 3,16 ; 3,09$ e 3,06, nas quatro frequências de aplicação, respectivamente para SB, 1 SAT, 90 DAT e 1 SAT + 90 DAT, conforme Figura 1D. Comparativamente com a polpa obtida de frutos sob manejo convencional da cultura, os valores foram superiores aos 2,68 e 3,44 obtidos por Silva et al. (2005) e Medeiros et al. (2009), avaliando a qualidade do suco do maracujazeiro-amarelo, respectivamente em diferentes estádios de maturação e genótipos.

$\mathrm{O}$ acúmulo de sais nos tecidos das plantas proveniente das $\mathrm{CE}_{\mathrm{a}}$ de 0,5 a 4,5 $\mathrm{dS} \mathrm{m}^{-1}$, provocou redução do $\mathrm{pH}$ no suco do maracujazeiro-amarelo, aumentando o caráter ácido dos frutos, no entanto, o aumento da frequencia de aplicação do biofertilizante resultou em menor decréscimo do $\mathrm{pH}$ da polpa, reduzindo a acidez em até $6 \%$ no tratamento $\mathrm{SB}$ e na $\mathrm{CE}_{\mathrm{a}}$ de 0,5 $\mathrm{dS} \mathrm{\textrm {m } ^ { - 1 }}$. O biofertilizante bovino, independentemente da frequência de aplicação, reduziu em aproximadamente $21 \%$ o $\mathrm{pH}$ da polpa dos frutos (Figura 1D), sendo que as aplicações realizadas aos 90 DAT e 1 SAT + 90 DAT, obtiveram os menores valores de $\mathrm{pH}$ com aumento da $\mathrm{CE}_{\mathrm{a}}$.

$\mathrm{O}$ pH ideal para o suco de maracujazeiro-amarelo, conforme Folegatti \& Matsuura (2002), não deve ser superior a 3,3 pois pode comprometer o processo de armazenamento. Por outro lado, Medeiros et al. (2009) afirmam que valores de $\mathrm{pH}$ de até 4,2 , comumente encontrados em suco de maracujazeiro-roxo, não comprometem o processo de industrialização mas permitem flexibilidade na adição de açúcares que varia de acordo com as características peculiares de cada mercado consumidor, principalmente o europeu, que tem preferência em consumir processados com características menos ácidas e com mais açúcar (Pinheiro et al., 2006).

Os valores da relação entre as concentrações de sólidos solúveis e a acidez titulável que expressam o sabor do suco, decresceram com o aumento da salinidade das águas e das frequências de aplicação do biofertilizante (Figura 2A).

Exceto nos tratamentos com água de $4,5 \mathrm{dS} \mathrm{m}^{-1}$ nas maiores frequências de aplicação do insumo orgânico (aos 90 DAT e 1 SAT + 90 DAT ), os valores da razão SST $\mathrm{AT}^{-1}$ não diferiram entre os tratamentos referentes às demais águas de irrigação com valores médios de 3,04 para a $\mathrm{Ce}_{\mathrm{a}}$ de 0,5 e 1,5 $\mathrm{dS} \mathrm{m}^{-1}$ e de
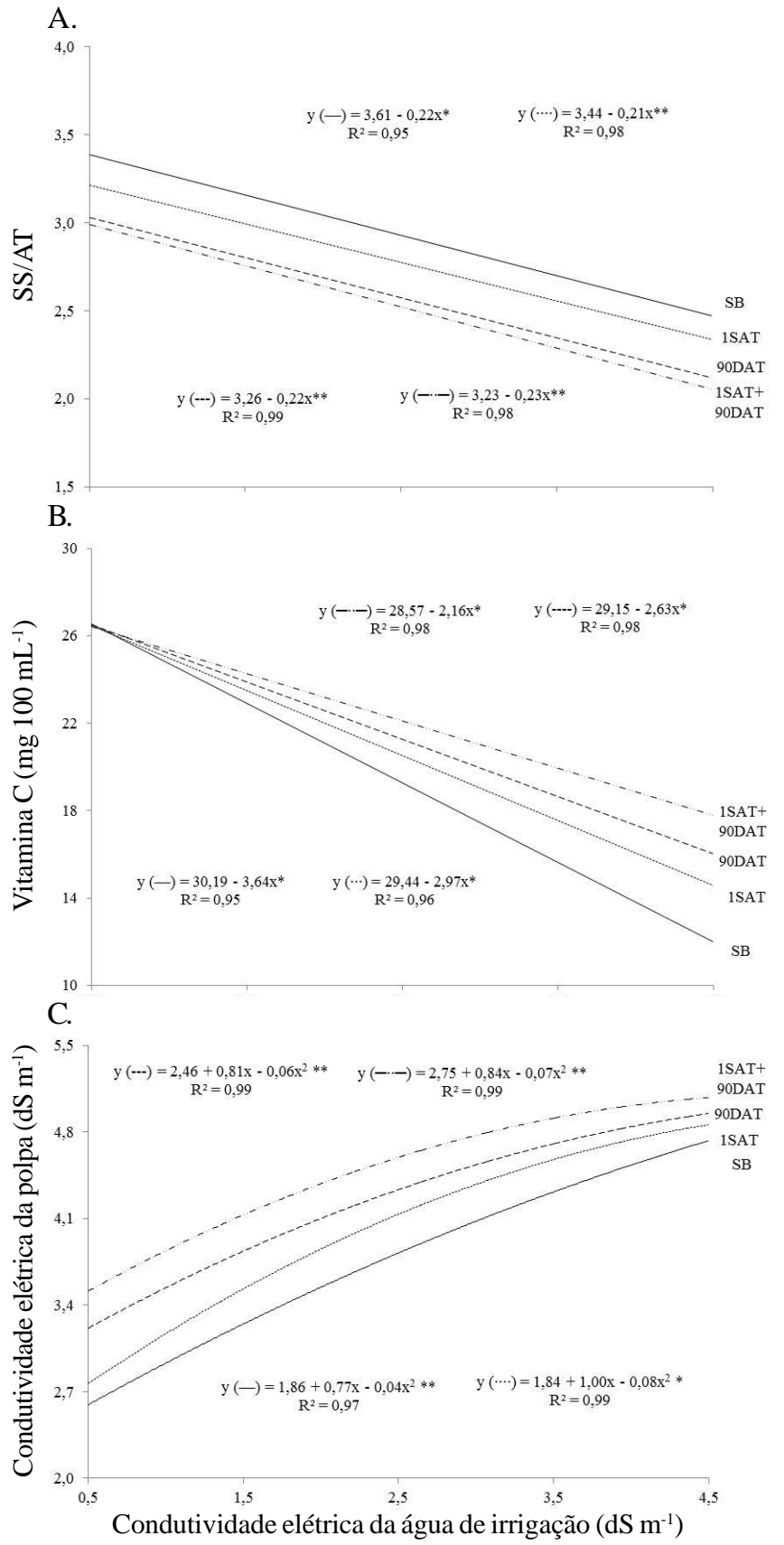

Figura 2. Valores da relação SS/AT (A), teores de vitamina " $C$ " (B) e condutividade elétrica (C) em polpa de frutos de maracujazeiro-amarelo irrigado com águas salinas em diferentes frequências de aplicação de biofertilizante

2,54 na $\mathrm{Ce}_{\mathrm{a}}$ de 2,5 e 3,5 $\mathrm{dS} \mathrm{m}^{-1}$ relativos à maior frequência de aplicação do biofertilizante bovino (Figura 2A). Quanto às aplicações do biofertilizante, a tendência dos dados esta em conformidade com Damatto Júnior et al. (2005), ao constatarem que a adubação orgânica aumentou a acidez dos frutos de maracujá-doce.

A razão SS/AT é considerada uma das formas mais rápidas de se avaliar o sabor dos frutos, visto que define o caráter doce-ácido, que representa o sabor das frutas (Pinheiro et al., 2006). Neste sentido, o sabor dos frutos obtidos no presente trabalho não se enquadra nos parâmetros admitidos como ótimos por Haendler (1965), com variação dos valores da razão 
SS/AT entre 4,2 e 5,2, porém estão próximos aos 3,1 obtidos por Cavalcante et al. (2005) e à variação entre 2,5 a 2,9 apresentada por Fischer et al. (2007) em sistema orgânico e convencional da cultura.

Os baixos valores da razão SS/AT são atribuídos à redução dos teores de sólidos solúveis totais e à elevação da acidez titulável, possivelmente em função dos efeitos dos ácidos orgânicos (Costa et al., 2001; Andrade \& Andrade, 2004).

O referido parâmetro, conforme Folegatti \& Matsuura (2002), representa uma das melhores formas de avaliação do grau de doçura do produto, mas pode ser influenciado pelo estádio de maturação do fruto, das condições de manejo da cultura, e reflete os possíveis estresses abióticos durante o processo de formação do fruto (Silva et al., 2008).

Os teores de vitamina "C" dos frutos foram reduzidos com o aumento da salinidade das águas e aumentaram com a frequência de aplicação do insumo orgânico (Figura 2B). A tendência de declínio da vitamina " $C$ " com a elevação do teor salino das águas está compatível com a redução dos teores de sólidos solúveis, evidenciado na Figura 2A, tendo em vista que a produção de vitamina "C" está relacionada aos açúcares presentes no suco dos frutos das plantas em geral, inclusive do maracujazeiro-amarelo, em que os frutos sintetizam o ácido ascórbico a partir de açúcares hexoses, originalmente D-glicose ou D-galactose (Fortaleza et al., 2005; Taiz \& Zeiger, 2006; Raimundo et al., 2009).

Os teores de vitamina " $C$ " (Figura 2C) não diferiram entre as águas de 0,5 e $1,5 \mathrm{dS} \mathrm{m}^{-1}$ nas frequências de aplicação do biofertilizante com valor médio entre as águas de 25,14 mg 100

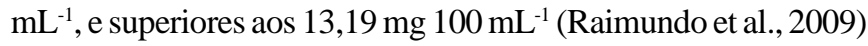
e semelhantes aos 23,62 mg $100 \mathrm{~mL}^{-1}$ (Costa et at., 2001). No entanto, nos tratamentos referentes às águas de 3,5 e 4,5 dS m${ }^{-1}$, os teores de vitamina " $C$ " foram superiores aos $20 \mathrm{mg} 100 \mathrm{~mL}^{-1}$, admitidos como adequados por Fischer et al. (2007), Rodrigues et al. (2008) e Raimundo et al. (2009).

O aumento do teor salino das águas de irrigação e da frequência de fornecimento do biofertilizante bovino, resultou na elevação da condutividade elétrica do suco dos frutos (Figura 2C). Os valores nos frutos foram elevados de 2,55 para 4,08 dS m $\mathrm{m}^{-1}$ em solo sem biofertilizante, de 2,72 para 4,58 dS m${ }^{1}$ com o insumo aplicado uma semana antes do transplantio, de 3,22 para 4,78 dS m $\mathrm{d}^{-1}$ referente ao biofertilizante aplicado a cada 90 dias após o transplantio e de 3,48 para $4,89 \mathrm{dS} \mathrm{m}^{-1}$ com o biofertilizante fornecido uma semana antes e a cada 90 DAT. Ao se considerar que águas de condutividade elétrica acima de $1,5 \mathrm{dS} \mathrm{m}^{-1}$ já oferecem restrição à maioria das plantas cultivadas, inclusive ao maracujazeiro-amarelo (Ayers \& Westcot, 1999), constata-se que o nível salino do suco está elevado. Tendência semelhante foi registrada por Cavalcante et al. (2003) após irrigarem o maracujazeiro-amarelo com águas de salinidade de 0,50 e 4,0 $\mathrm{dS} \mathrm{m}^{-1}$ e verificar que o aumento da salinidade da água de irrigação elevou o teor salino da polpa dos frutos.

Para Mendlinger (1994), o aumento do teor salino do solo eleva a condutividade elétrica a ponto de comprometer a qualidade pós-colheita dos frutos. Esta situação é preocupante, de vez que a qualidade pós-colheita dos frutos pode ser prejudicada pela natureza e concentração de íons, solubilidade, mobilidade iônica e viscosidade (Moura et al., 1999), resultantes do nível de estresse salino e do grau de tolerância da cultura.

A condutividade elétrica do substrato observada na Tabela 2, foi determinada imediatamente após mistura dos componentes solo e esterco bovino, apresentando valores considerados elevados de 7,84 $\mathrm{dS} \mathrm{m}^{-1}$ em decorrência, provavelmente, da adubação de fundação e do esterco bovino, que apresentam potencialidade de disponibilizar quantidades apreciáveis de sais (Benites \& Mendonça, 1998; Oliveira et al., 2009); no entanto, três meses após o preparo dos substratos nos lisímetros, antes da aplicação dos tratamentos, em decorrência, sem dúvidas, provavelmente das precipitações e da mineralização do material orgânico, a condutividade elétrica do substrato reduziu para 3,66 dS m $\mathrm{m}^{-1}$, valor considerável adequada a cultura do maracujazeiro-amarelo (Cavalcante et al., 2006).

\section{CONCLUSÕES}

1. O aumento salino das águas de irrigação resultou em perdas do rendimento em polpa, de sólidos solúveis, razão SS $\mathrm{AT}^{-1}$ e de vitamina "C" do suco de maracujazeiro-amarelo.

2. O aumento da salinidade das águas elevou a acidez titulável e o caráter salino do suco.

3. O aumento das frequências de aplicação do biofertilizante bovino estimulou o rendimento em polpa, acidez titulável, teores de vitamina "C" e a condutividade elétrica do suco.

\section{LITERATURA CITADA}

AGRIANUAL - Anuário da Agricultura Brasileira. São Paulo: FNP, 2009. v.1, p.371-372.

Andrade, J. M. B.; Andrade, A. B. Características físico-químicas do maracujá amarelo produzido em diferentes épocas em Marumbi-PR. Arquivo Apadec, Meio Ambiente, p.391-397, 2004.

Araújo, L. A.; Alves, A. S.; Andrade, R.; Santos, J. G. R.; Costa, C. L. L. Comportamento do maracujazeiro-amarelo (Passiflora edulis $f$. Sims flavicarpa Deg.) sob diferentes dosagens de biofertilizante e intervalos de aplicação. Revista Verde de Agroecologia e Desenvolvimento Sustentável, v.3, p.98-109, 2008.

Ayers, R. S.; Westcot, D. W. A qualidade de água na agricultura. 2.ed. Campina Grande: UFPB, 1999. 153p. FAO. Estudos Irrigação e Drenagem, 29 revisado 1.

Benites, V. M.; Mendonça, E. S. Propriedades eletroquímicas de um solo eletropositivo influenciadas pela adição de diferentes fontes de matéria orgânica. Revista Brasileira de Ciências do Solo, v.22, p.215-221, 1998.

Cavalcante, L. F.; Andrade, R.; Costa, J. R. M.; Cavalcante, I. H. L.; Gondim, S. C.; Lima, E. M.; Macedo, J. P. S.; Santos, J. B.; Santos, C. J. O. Maracujá-amarelo e a salinidade. In: Cavalcante, L. F.; Lima, E. M. de. (ed.). Algumas frutíferas tropicais e a salinidade. Jaboticabal: FUNEP, 2006. p.91-115. 
Cavalcante, L. F.; Andrade, R.; Mendonça, R. M. N.; Silva, S. M.; Oliveira, M. R. T.; Araújo, F. A. R.; Cavalcante, I. H. L. Caracterização qualitativa de frutos de maracujá-amarelo (Passiflora edulis f. flavicarpa Deg.) em função da salinidade da água de irrigação. Agropecuária Técnica, v.24, p.39-45, 2003.

Cavalcante, L. F.; Dantas, T. A. G.; Andrade, R.; Sá, J. R.; Macedo, J. P. da S.; Gondim, S. C.; Cavalcante, Í. H. L. Resposta do maracujazeiro amarelo à salinidade da água sob diferentes formas de plantio. Revista Brasileira de Engenharia Agrícola e Ambiental, v.9, p.314-317, 2005.

Cavalcante, L. F.; Silva, G. F. da; Gheyi, H. R.; Dias, T. J.; Alves, J. do C.; Costa, A. de P. M. da. Crescimento de mudas de maracujazeiro amarelo em solo salino com esterco bovino líquido fermentado. Revista Brasileira de Ciências Agrárias, v.4, p.414-420, 2009.

Cavalcante, L. F.; Vieira, M. S.; Santos, A. F.; Oliveira, W. M.; Nascimento, J. A. M. Água salina e esterco bovino líquido na formação de mudas de goiabeira cultivar Paluma. Revista Brasileira de Fruticultura, v.32, p.251-261. 2010.

Coelho, M. A.; Soncin, N. B. Geografia do Brasil. São Paulo: Ed. Moderna. 1982.368p.

Costa, J. R. M.; Lima, C. A. de A.; Lima, E. D. P. de A.; Cavalcante, L. F.; Oliveira, F. K. D. de. Caracterização dos frutos de maracujá amarelo irrigados com água salina. Revista Brasileira de Engenharia Agrícola e Ambiental, v.5, p.143146, 2001.

Damatto Júnior, E. R.; Leonel, S.; Pedroso, C. J. Adubação orgânica na produção e qualidade de frutos de maracujazeiro-doce. Revista Brasileira de Fruticultura, v.27, p.188-190, 2005.

Fischer, I. H.; Arruda, M. C.; Almeida, A. M.; Garcia, M. J. M.; Jeronimo, E. M.; Pinotti, R. N.; Bertani, R. M. A. Doenças e características físicas e químicas pós-colheita em maracujá amarelo de cultivo convencional e orgânico no Centro Oeste paulista. Revista Brasileira de Fruticultura, v.29, p.254-259, 2007.

Folegatti, M. I. S.; Matsuura, F. C. A. U. Produtos. In: Matsuura, F. C. A. U.; Folegatti, M. I. S. (ed.). Maracujá pós-colheita. Brasília: EMBRAPA, 2002. p.42-47.

Fortaleza, J. M.; Peixoto, J. R.; Junqueira, N. T. V.; Oliveira, A. T.; Rangel, L. E. P. Características físicas e químicas em nove genótipos de maracujá azedo cultivado sob três níveis de adubação potássica. Revista Brasileira de Fruticultura, v.27, p.124-127, 2005.

Freitas, M. S. M.; Monnerat, P. H.; Pinho, L. G. da R.; Carvalho, A. J. C. de. Deficiência de macronutrientes e boro em maracujazeiro doce: qualidade dos frutos. Revista Brasileira de Fruticultura, v.28, p.492-496, 2006.

Gondim, S. C.; Cavalcante, L. F.; Campos, V. B.; Mesquita, E. F.; Gondim, P. C. Produção e composição foliar do maracujazeiro amarelo sob lâminas de irrigação. Caatinga, v.22, p.100-107, 2009.

Gurgel, M. T.; Fernandes, P. D.; Gheyi, H. R.; Santos, F. J. de S.; Bezerra, I. L.; Nobre, R. G. Índices fisiológicos e de crescimento de um porta-enxerto de aceroleira sob estresse salino. Revista Brasileira de Engenharia Agrícola e Ambiental, v.7, p.451-456, 2003.
Gurgel, M. T.; Uyeda, C. A.; Gheyi, H. R.; Oliveira, F. H. T. de; Fernandes, P. D.; Silva, F. V. da. Crescimento de meloeiro sob estresse salino e doses de potássio. Revista Brasileira e Engenharia Agrícola e Ambiental, v.14, p.3-10, 2010.

Haendler, L. La passiflora: Sa composition chimique et ses possibilités de transformation. Fruits, v.20, p.235-245, 1965.

Instituto Adolfo Lutz. Normas analíticas, métodos químicos e físicos para análise de alimentos. 3.ed. São Paulo: Instituto Adolfo Lutz, 1985. 533p.

Maas, E. V. Crop salt tolerance. In: Tanji, K. K. (ed.). Agricultural salinity assessment and management. New York: Americam Society of Civil Engineers, 1990. p.262-304.

Marinho, F. J. L.; Gheyi, H. R.; Fernandes, P. D.; Ferreira Neto, M. Alterações fisiológicas em coqueiro irrigado com água salina. Revista Brasileira de Engenharia Agrícola e Ambiental, v.5, p.370-374, 2005.

Medeiros, S. A. F.; Yamanishi, O. K.; Peixoto, J. R.; Pires, M. C.; Junqueira, N. T. V.; Ribeiro, J. G. B. L. Caracterização físicoquímica de progênies de maracujá-roxo e maracujá-azedo cultivados no Distrito Federal. Revista Brasileira de Fruticultura, v.31, p.492-499, 2009.

Meletti, L. M. M.; Soares Scott, M. D.; Bernacci, L. C.; Azevedo, F. J. A. Desempenho das cultivares IAC-273 e IAC-277 de maracujazeiro-amarelo (Passiflora edulis f. flavicarpa Deg.) em pomares comerciais. In: Reunião Técnica de Pesquisa em Maracujazeiro, 3, 2002, Viçosa. Anais...Viçosa: UFLA, 2002.p.196-197.

Mendlinger, S. Effect of increasing plant density and salinity on yield and fruit quality in muskmelon. Scientia Horticulturae, v.57, p.41-49, 1994.

Moura, S. C. S. R.; Vitali, A. A.; Hubinger, M. D. A study of water activity and electrical conductivity in fruit juices: Influence of temperature and concentration. Brazilian Journal Food Technology, v.2, p.31-38, 1999.

Oliveira, H. V.; Bezerra Neto, F.; Azevedo, C. M. S. B. A.; Lima, C. B.; Gurgel, G. C. S. Alterações nas características químicas de um Argissolo Vermelho-Amarelo irrigado com efluente de piscicultura, em ambiente protegido. Revista Agro@mbiente,v.3,p.9-14, 2009.

Pimentel, L. D.; Santos, C. E. M.; Ferreira, A. C. C.; Martins, A. A.; Wagner Júnior, A.; Bruckner, C. H. Custo de produção e rentabilidade do maracujazeiro no mercado agroindustrial da Zona da Mata Mineira. Revista Brasileira de Fruticultura, v.31, p.397-407, 2009.

Pinheiro, A. M.; Fernandes, A. G.; Fai, A. E. C.; Prado, G. M. do; Sousa, P. H. M. de; Maia, G. A. Avaliação química, físicoquímica e microbiológica de sucos de frutas integrais: Abacaxi, caju e maracujá. Ciência e Tecnologia de Alimentos, v.26, p.98-103, 2006.

Porto Filho, F. Q.; Medeiros, J. F. de; Senhor, R. F.; Morais, P. L.; Menezes, J. B. Qualidade de frutos do melão amarelo irrigado com água de diferentes níveis de salinidade. Revista Caatinga, v.22, p.193-198, 2009.

Raimundo, K.; Magri, R. S.; Simionato, E. M. R. S.; Sampaio, A. C. Avaliação física e química da polpa de maracujá congelada comercializada na região de Bauru. Revista Brasileira de Fruticultura, v.31, p.539-543, 2009. 
Ribeiro, A. C.; Guimarães, P. T. G.; Alvarez, V. H. Recomendações para o uso de corretivos e fertilizantes em Minas Gerais $5^{\mathrm{a}}$ aproximação. Viçosa: Comissão de Fertilidade do Solo do Estado de Minas Gerais, 1999. 359p.

Rodolfo Júnior, F.; Cavalcante, L. F.; Buriti, E. de S. Crescimento e produção do maracujazeiro-amarelo em solo com biofertilizantes e adubação mineral com NPK. Caatinga, v.21, p.134-145, 2008.

Rodrigues, A. C.; Cavalcante, L. F.; Dantas, T. A. G.; Campos, V. B.; Diniz, A. A. Caracterização de frutos de maracujazeiro amarelo em solo tratado com biofertilizante supermagro. Magistra, v.20, p.264-272, 2008.

Sampaio, A. C.; Fumis, T. de F.; Almeida, A. M. de; Pinotti, R. N.; Garcia, M. J. de M.; Pallamin, M. L. Manejo cultural do maracujazeiro-amarelo em ciclo anual visando à convivência com o vírus do endurecimento dos frutos: um estudo de caso. Revista Brasileira de Fruticultura, v.30, p.343-347, 2008.

Santos, A. C.; Akiba, F. Biofertilizantes líquidos: Uso correto na agricultura alternativa. Seropédica: Imprensa Universitária/ UFRRJ. 1996.35p.

SAS. SAS user's guide: Statistical analysis system, Release 8.0. Cary: SAS Institute, 2000. 544p.

Silva, D. L. V. da; Alves, R. E.; Figueiredo, R. W.; Maciel, V. T.; Farias, J. M. de; Aquino, A. R. L. Características físicas, físico-químicas e sensoriais da água de frutos de coqueiro anão verde oriundo de produção convencional e orgânica. Ciência e Agrotecnologia, v.33, p.1079-1084, 2009.

Silva, E. N.; Silveira, J. A. G.; Rodrigues, C. R. F.; Lima, C. S.; Viégas, R. A. Contribuição de solutos orgânicos e inorgânicos no ajustamento osmótico de pinhão-manso submetido à salinidade. Pesquisa Agropecuária Brasileira, v.44, p.437-445, 2009.
Silva, P. S. L.; Sá, W. R.; Mariguele, K. H.; Barbosa, A. P. R.; Oliveira, D. F. Distribuição do teor de sólidos solúveis totais em frutos de algumas espécies de clima temperado. Caatinga, v.15, p.19-23, 2002.

Silva, T. V.; Resende, E. D.; Viana, A. P.; Pereira, S. M. F.; Carlos, L. A.; Vitorazi, L. Qualidade do suco de maracujá-amarelo em diferentes épocas de colheita. Ciências e Tecnologia de Alimentos, v.28, p.545-550, 2008.

Silva, T. V.; Resende, E. D.; Viana, A. P.; Rosa, R. C. C.; Pereira, S. M. de F.; Carlos, L. de A.; Vitorazi, L. Influência dos estádios de maturação na qualidade do suco do maracujáamarelo. Revista Brasileira de Fruticultura, v.27, p.472-475, 2005.

Soares, F. A. L.; Carneiro, P. T.; Gomes, E. M.; Gheyi, H. R.; Fernandes, P. D. Crescimento e produção do maracujazeiro amarelo sob irrigação suplementar com águas salinas. Revista Brasileira de Ciências Agrárias, v.3, p.151-156, 2008.

Souza, G. B. de; Cavalcante, L. F.; Cavalcante, I. H. L.; BeckmanCavalcante, M. Z.; Nascimento, J. A. M. do. Salinidade do substrato contendo biofertilizante para a formação de mudas de maracujazeiro irrigado com água salina. Caatinga, v.21, p.172-180, 2008.

Taiz, L.; Zeiger, E. Fisiologia vegetal. 3.ed. Porto Alegre: Artmed, 2006. 719p.

Tester, M.; Davenport, R. $\mathrm{Na}^{+}$tolerance and $\mathrm{Na}^{+}$transport in higher plants. Annals of Botany, v.91, p.503-527, 2003.

Tocchini, R. P.; Nisida, A. L. A. C.; Hashizume, T.; Medina, J. C.; Turatti, J. N. Processamento: Produtos, caracterização e utilização. In: ITAL. Maracujá: Cultura, matéria-prima, processamento e aspectos econômicos. Campinas: ITAL, 1994. p.161-196. 